\title{
A JUDICIALIZAÇÃO DOS CONFLITOS ESCOLARES
}

\author{
THE JUDICIALIZATION OF SCHOOL CONFLICTS
}

\author{
Elisiane Spencer Quevedo Goethel ${ }^{1, *}$ \\ Caroline Polido ${ }^{1}$ \\ Débora Cristina Fonseca ${ }^{1}$
}

RESUMO: Este artigo tem como objetivo discutir a judicialização das relações escolares e os aspectos punitivos e educativos das ações tomadas pela escola. Para tanto, foram analisados processos judiciais de alunos do Ensino Fundamental II que tiveram sua origem por iniciativa da escola. Trata-se de uma pesquisa documental de análise qualitativa, na qual foi utilizada a técnica de análise de conteúdo. O estudo aponta que as situações de violência ocorridas no âmbito da escola estão sendo direcionadas para o sistema de justiça na tentativa de que o conflito seja afastado e resolvido fora da escola.

Palavras-chave: Conflitos escolares. Judicialização. Escola. Ato infracional.

\begin{abstract}
This article aims to discuss the judicialization of school relations, as well as the punitive and educational aspects of the actions taken by the school. To reach this goal, judicial proceedings, iniciated by the iniciative of the school against elementary students, were analyzed. This paper is a documentary research of qualitative analysis, where the technique of content analysis was applied. The study points out that situations of violence occurring within the school are being directed to the justice system in an attempt to have the conflict removed and resolved out of school.
\end{abstract}

Keywords: School conflicts. Judicialization. School. Infraction act.

1.Universidade Estadual Paulista Júlio de Mesquita Filho - Instituto de Biociências - Departamento de Educação - Rio Claro/SP, Brasil. E-mails: lisispencer@gmail.com, caroline_poli@hotmail.com, debora.fonseca@unesp.br

*Autora correspondente: lisispencer@gmail.com

Dossiê organizado por: Joyce Mary Adam e Débora Cristina Fonseca 


\section{Introdução}

Problemas cotidianos costumeiramente denominados conflitos escolares têm se evidenciado cada vez mais nas escolas. Geralmente, propaga-se que há um vertiginoso aumento de atos "violentos" dentro das instituições escolares, fato que resultaria da má educação dos alunos e do fracasso das famílias na criação de seus filhos. Tais argumentos, geralmente analisados de maneira simplória e ancorada em conhecimentos de senso comum, deixam de considerar as mudanças socioculturais das sociedades.

Por muitos anos, a escola foi uma instituição hierarquizada, a qual tinha como público, predominantemente, a classe burguesa. Com a redemocratização do país, na década de 1980, a sociedade como um todo passou a ter o direito de adentrar as instituições escolares, com sua diversidade, história e contexto social. Com a promulgação da Constituição Federal de 1998, a educação tornou-se um direito de todos. Nesse novo cenário, a Lei de Diretrizes e Bases da Educação Nacional (n. 9.394, de 20 dez. 1996) trouxe diversas mudanças em relação às LDB antecedentes, validando o que já estava previsto na Constituição Federal de 1988 no que se refere ao dever do Estado de garantir o Ensino Fundamental, obrigatório e gratuito, inclusive para os que a ele não tiveram acesso na idade própria. Garantiu-se também a progressiva universalização do Ensino Médio gratuito, que inclui a obrigatoriedade do Ensino Médio com a Lei n. 12.061/2009, que altera a LDB. Contudo, é notório que esse direito ainda não se efetiva plenamente, conforme podemos observar nos dados da Pesquisa Nacional por Amostra de Domicílios Contínua (PNAD), que aponta que quase 4 em cada 10 jovens de 19 anos não concluíram o Ensino Médio, sendo que, entre eles, 62\% estavam fora da escola e 55\% pararam de estudar ainda no Ensino Fundamental (IBGE, 2019).

Com esse novo cenário a escola se transforma em um espaço que comporta as diversidades e pluralidades da sociedade, por meio dos sujeitos que ali têm o direito de estar. Assim, a escola é constituída por indivíduos que são expostos a universos sociais diferenciados (classes sociais, estrutura familiar, entre outros), a espaços de socialização múltiplos, heterogêneos e concorrentes, e que, por consequência, têm suas referências sociais ampliadas (LAHIRE, 2002).

Nesse sentido, a função socializadora da escola, segundo Dayrell (2014), vive uma crise da eficácia motivada pela gradual perda do monopólio da instituição no processo de formação das novas gerações. Os alunos já não são mais os mesmos que faziam parte de um único sistema. Dessa maneira, segundo o autor, "os jovens da atual geração vêm se formando, se constituindo como atores sociais de uma forma muito diferente das gerações anteriores, numa mudança de tempos e espaços de socialização" (DAYRELL, 2014, p. 301).

Todo esse universo entra em choque com as "novas" ainda "velhas" escolas, que guardam amarras dos tempos anteriores à democratização da educação e que:

esperam alunos, e o que recebem são sujeitos de múltiplas trajetórias e experiências de mundo, muitas delas oriundas de redes de relacionamento produzidas nos espaços-tempos da Internet, dos mercados de consumo, de grupos culturais juvenis ou intergeracionais, de grupos religiosos e de culturas criativas e periféricas (DAYRELL, 2014, p. 127).

Nessas circunstâncias, introduzem-se as análises deste texto, a partir de pesquisa realizada nos processos judiciais de jovens delatados pelas escolas. Não é surpresa que uma grande transformação de cenário acarrete implicações positivas e negativas. Entre tais implicações, pode-se apontar a massificação da educação, que trouxe um novo conjunto de alunos para uma escola que se manteve 
estática na rotina e na relação, tendo como consequência um descompasso entre o aluno real e o aluno que se imagina ter. Dessa maneira, vivenciamos o fenômeno da judicialização, palavra que se refere à "necessidade de recorrer ao âmbito da justiça para a obtenção de um direito negado ou para a reparação de algum dano" (SCHMIDT, 2007, p. 59).

Diante das relações de conflito cotidianas em nossa sociedade, a escola passou a reconhecer/ nomear a ocorrência de atos infracionais para práticas antes consideradas indisciplinares. Quando esse processo acontece, o problema sai da esfera escolar para atingir o sistema de garantia de direitos, ou seja, o Conselho Tutelar (quando praticado por criança) ou polícia (civil e militar), Ministério Público e Poder Judiciário (quando o ato infracional for praticado por adolescente).

No que se refere ao âmbito escolar, podemos evidenciar registros nos Livros de Ocorrência Escolar (LOE), que se compõem de instrumentos bastante utilizados para enquadrar como possíveis infratores os jovens reconhecidos como protagonistas de violência dentro da escola. Nessa perspectiva, observa-se que a escola colabora para a criminalização dos atos praticados em seu ambiente, não necessariamente atos de violência, mas que, ao serem assim significados, podem dar inicio a um processo judicial. Entendemos que, diante dessa conduta, a escola descaracterize sua função pedagógica, dado que estudos têm identificado que os LOE não possuem caráter pedagógico, mas punitivo/repressivo, e funcionam como uma espécie de dossiê/provas contra os alunos.

A escola tem um peso relevante na vida dos alunos, principalmente dos jovens que vivem em condições de vulnerabilidade social, os quais acabam por encontrar nela uma parte do cuidado de que tanto precisam. Contudo, algumas instituições dificultam o processo de garantia à vaga, que é de direito do aluno, e outras, mesmo depois de terem aceito tais jovens, hostilizam, discriminam e não oferecem suporte necessário para que possam dar continuidade aos estudos e nelas permanecerem. Avaliamos que esses elementos, somados a outros da vida do jovem, podem ser os responsáveis pelos inúmeros casos de evasão. Como já apontado por Zaluar e Leal, quando a escola não acolhe o adolescente, a criminalidade que existe fora da escola o acolhe (2001), tornando as reintegrações escolar e social um grande desafio para a escola, para a sociedade e para o Estado.

A partir do panorama explicitado, neste artigo trataremos da judicialização das relações escolares, discutindo os aspectos punitivos e educativos das ações tomadas pela escola diante de conflitos nela enfrentados e registrados, com base em uma perspectiva sócio-histórica (VIGOTSKI, 2001).

\section{Metodologia}

A pesquisa desenvolvida, de caráter qualitativo, utilizou-se de análises documental e de conteúdo para a sistematização dos dados. Os dados foram levantados em oito processos judiciais de alunos de Ensino Fundamental II de uma escola localizada na periferia de uma cidade do interior paulista. Os processos tiveram sua origem por iniciativa da escola.

A partir de dados dos Livros de Ocorrência Escolar (LOE) e de entrevistas com a equipe gestora, chegou-se aos nomes dos jovens entendidos como protagonistas de violência pela escola. Em seguida, os nomes foram pesquisados no sistema do Tribunal de Justiça, chegando aos oito processos analisados.

As infrações registradas nos processos judiciais são: dano, ameaça, vias de fato e desacato. Quatro processos foram instaurados no ano de 2012 e os outros quatro no ano de 2013. O tempo médio de duração dos processos foi de um ano, da entrada no judiciário até o arquivamento. 


\section{Resultados e Discussão}

Ao analisarmos todos os documentos, observamos que, nas mais variadas situações, a escola julgou ser necessária intervenção de um órgão externo à unidade escolar. Nos oito processos estudados, constava que a Polícia Militar foi chamada para intervir nos fatos ocorridos, apontando que a instituição de ensino entendeu que os atos necessitavam da intervenção de terceiros para a resolução do conflito.

Ao todo, foram efetuados sete boletins de ocorrência (que deram origem aos processos analisados), sendo que, em seis deles, os adolescentes foram conduzidos até a delegacia.

Para que possamos entender o enredo narrado nos boletins de ocorrência e os fatos impostos aos adolescentes, apresentamos trechos constantes no campo "histórico", redigidos pela polícia e apresentados no trabalho de Goethel (2016):

A Polícia Militar foi acionada a comparecer na escola, onde foi informado que no dia anterior os adolescentes teriam danificado a moto da professora Raimunda, cortando a mangueira de combustível. Segundo a direção da escola a criança Mateus estava junto quando do ocorrido. Só perceberam o ocorrido um dia depois (Caso 1- André e Jonatas, fl. 06).

Consta no B.O. que a ronda escolar em visita à escola "tomou conhecimento de que um adolescente, de nome Charles teria ameaçado a vítima, que é funcionária da escola, enquanto que o adolescente Vitor teria danificado o caderno escolar, sendo que ambos já foram advertidos e suspensos anteriormente" (Caso 2 - Charles e Vitor, fl. 05).

Alguns alunos tinham danificado o projeto, sendo um painel que tinha colocado na parede, e que o adolescente estava atrás da porta ouvindo a conversa, e que ele achou que estava falando dele e a ameaçou, dizendo: "que não sabia com quem estava mexendo", e que iria estourar a cara dela. Nada mais (Caso 3 -Luciano, fl. 05).

Dentro da sala de aula, os adolescentes se agrediram. Que foram orientados a passar por atendimento médico após o término da ocorrência apesar de não apresentarem lesões (Caso 4 - Fernando e Natália, fls. 04 e 05).

Em contato com a vítima, a mesma relatou que é inspetora de alunos estava no corredor da escola quando a adolescente saiu da sala com celular ligado em som alto; que pediu a mesma que abaixasse o som, momento este em que adolescente se recusou, vindo a ofender a vítima, dizendo: cala a boca! Vai à merda! Você não manda em mim! Não vou abaixar nada! (sic), vindo a ameaçá-la dizendo: toma cuidado comigo! Você não sabe do que sou capaz! (sic). Através da direção da escola, foi tentado contato com os responsáveis, no entanto sem êxito. Foi acionada a conselheira tutelar, a qual compareceu e ficou responsável pela adolescente conforme termo de compromisso (Caso 6 - Beatriz, fl.07).

Em contato com a professora [...] esta relatou que já faz algum tempo que a aluna vem apresentando comportamento inadequado em sala de aula, além de proferir diversas palavras de baixo calão dirigindo desta forma aos demais alunos, bem como com a professora. Que na data de ontem a adolescente disse que iria bater na professora, da 
mesma forma que fez com outro adulto. Que na data de hoje veio a repetir os xingamentos e ainda ameaçou dizendo: você não sabe com quem está lidando, vindo em seguida a empurrar a cadeira da professora. Foi efetuado contato com a genitora da adolescente, a qual se recusou a comparecer. Foi assinado o Conselho Tutelar, tendo comparecido a conselheira [...], sendo que a adolescente negou-se a prestar declarações na presença desta, como também se recusou a acompanhá-la até sua residência, bem como retornar à escola alegando que iria com suas próprias pernas. A conselheira tutelar também não pode se responsabilizar pela apresentação da adolescente, desta forma esta autoridade policial oficiou a Vara da Infância e da Juventude (Caso 7 - Beatriz, fl. 8).

Como se observa, os casos apresentados não consistem em situações de extrema gravidade, sendo algumas delas corriqueiras em ambiente escolar, já que os jovens acabam desafiando ordens e regras impostas pela instituição. Como aponta Dubet (2003), dentro da escola existe uma tensão criada pelos alunos, que tendem a demonstrar aos seus colegas indiferença e descompromisso com as regras, na expectativa de serem reconhecidos pelos colegas estudantes ao desafiarem a autoridade representada em tais regras.

Os casos judicializados, em sua maioria, foram atribuídos ao crime de ameaça. Essa atitude de afronta a professor/funcionários pode caracterizar desafio à autoridade que a pessoa em questão representa ou, ainda, diferentes formas de significar as palavras e os sentidos produzidos. Ao mesmo tempo que, para a inspetora, as palavras proferidas pela adolescente foram entendidas como ameaça, para a menina, não houve a mesma conotação, não carregavam essa intencionalidade (GOETHEL, 2016). Essas discrepâncias de entendimento podem ser analisadas na perspectiva proposta por Vigotski (2001), que considera que significado e sentido são constitutivos do modo como cada um apreende o mundo, sendo diferentes, mas não indissociáveis. Os significados, constituídos nas palavras, podem se modificar conforme os sentidos atribuídos, ou seja, de acordo com a construção subjetiva de cada pessoa: os sentidos se manifestam por meio das palavras (significados socialmente partilhados). Na perspectiva vigotskiana, podemos apreender os sentidos como uma formação dinâmica, fluida e complexa, com várias zonas de estabilidade, e o significado como o elemento socialmente partilhado. Nessa relação entre sentido e significado, o autor indica que "[o]significado é apenas uma dessas zonas de sentido que a palavra adquire no contexto de algum discurso e, ademais, uma zona mais estável, uniforme e exata” (VIGOTSKI, 2001, p. 465).

Assim sendo, os sentidos são mais amplos e podem ser enunciados por diferentes palavras, conforme a constituição subjetiva de cada um, pelo caráter volitivo dos significados.

Para uma compreensão melhor, considerando essa relação dialética, os sentidos foram cunhados por Rey (2004) como “sentido subjetivo ou pessoal”. Na perspectiva vigotskiana, epistemologicamente, essa nomeação indica redundância, mas permite a compreensão materializada e histórica dessa dimensão subjetiva. Logo, os significados socialmente partilhados (palavras) constituem uma das zonas de estabilidade dos sentidos.

Nesta lógica, podemos dizer que existem diferentes zonas de sentido mediando o ambiente escolar, mas que o significado acaba constituindo elemento fundamental assumido por aqueles que representam a escola, em seu modo próprio de apreender. Portanto, os sentidos que tendem a prevalecer são produzidos por aqueles que ocupam um lugar de autoridade, não pelos estudantes ou por todos os envolvidas no conflito. Um exemplo pode ser observado no Caso 6, apresentado por Goethel (2016, p.94). No relato de Beatriz consta: 
pedi para o professor para ir tomar água e os meninos disseram que a inspetora era chata e não nos deixaria tomar água. Quando saí da sala, ela estava no corredor, no momento em que o fone de ouvido caiu, ficando o som do celular alto, quando ela me disse que eu não poderia usá-lo na escola, me mandando desligar e entrar na sala, quando respondi que ela não mandava em mim, mandei-a tomar no cu, se foder. Nesse momento, ela tentou me pegar, então disse para ela tirar a mão de mim, que você não é minha mãe (Caso 6, fl. 11v).

Nesse relato, torna-se evidente que a interação dialógica foi atravessada pelo modo como cada um significa a situação e pelos sentidos produzidos por cada um diante dos fatos. Notabiliza-se que a adolescente não aceita rigorosamente as regras escolares. Faz uso do celular, o que é proibido por lei estadual, e não acata as ordens colocadas pela inspetora de alunos naquele momento.

Questionamos se desrespeito às regras escolares pode ser compreendido como ato infracional e se os "insultos" proferidos pela adolescente tiveram, verdadeiramente, para ela, um sentido de ameaça. Provavelmente não. Entretanto, a reação da estudante à repreensão da ordem local acaba por incidir em uma ação que pode ser considerada infração. Cabe ainda questionar, nesse contexto, se a adolescente tem compreensão, esclarecimento, discernimento do que a levou a cometer ato infracional ou foi assim considerado.

Em outra ocasião, segundo os registros no processo, a mesma aluna afrontou a professora dizendo: "você não sabe com quem está lidando", uma atitude desafiante na perspectiva da equipe gestora e dos docentes, como pode ser depreendido da lei. O relato da professora, a seguir, mostra o entendimento de que Beatriz vem "chamando a atenção", quando conta que "já faz algum tempo que a aluna vem apresentando comportamento inadequado em sala de aula, além de proferir diversas palavras de baixo calão dirigindo, dessa forma, aos demais alunos, bem como à professora" (GOETHEL, 2016).

Embate e não reconhecimento de autoridade estão presentes também no Caso 3 (GOTHEL, 2016), no qual o aluno Luciano ameaçou a professora após ela o ter acusado de danificar um painel de propriedade da escola. O estudante não reconheceu a autoria, que considerou falsa acusação, e justificou sua atitude para o promotor de justiça afirmando que proferiu a ameaça porque estava nervoso. Na manifestação de Luciano, ele teria dito para a professora: “você vai ver então". Observe-se que o estudante não havia produzido uma ameaça no sentido percebido pela professora. Contudo, as palavras, na condição de zona de sentido, tomaram essa proporção, sendo que, para o estudante, nem ao menos representaram uma ameaça. Mais uma vez, entrevê-se que o adolescente não tem a mesma percepção da magnitude da ameaça como comportamento criminalizado.

Cabe refletir sobre o fato de que a percepção do que é ou não ameaça depende dos envolvidos, que identificam seus atos e palavras e lhes atribuem sentidos. Fica evidente que há recusa à disciplina escolar e validação das condutas, por serem entendidas como injustas. Outra compreensão é que os alunos não se sentem pertencentes à escola e às suas regras, manifestando esse sentimento quando enxergam os professores/funcionários como seus opositores/inimigos. Leontiev (1978) entende que os sentidos fazem parte do conteúdo da consciência e parecem adentrar a significação objetiva, sendo o sentido aquilo que se exprime nas significações, não a significação aquilo que se exprime nos sentidos. Assim, o sentido de não pertencimento se exprime em seus comportamentos ou formas de se apresentar às autoridades escolares. 
Em todos esses casos, a polícia foi chamada, foi até a escola e registrou a ocorrência.

Quando a PM é chamada até o local dos fatos, ela ouve as partes e registra em formulário próprio todos os dados relevantes. Esse documento será encaminhado para a Polícia Civil e será informatizado, ou seja, o formulário preenchido e assinado pelas partes ainda na escola nada mais é do que o próprio B.O., que será encaminhado juntamente com outros documentos para o Ministério Público. É necessário deixar claro que esse é um dos trâmites possíveis para a realização do B.O. (GOETHEL, 2016, p. 96).

Não analisaremos a postura adotada pela PM de conduzir os adolescentes até a delegacia. Vamos nos ater, neste artigo, a refletir sobre a posição/ação da escola. Cruzando os registros dos processos, podemos perceber que os alunos conduzidos até a delegacia o foram em horário de aula, como se observa na Tabela 1.

Tabela 1.Horário de aula versus horário de condução até a delegacia.

\begin{tabular}{|c|c|c|}
\hline Caso - Adolescente & Informação no processo & Horário de Condução à Delegacia* \\
\hline Caso 1 - André & $\begin{array}{c}\text { Estava no intervalo, foi informado pela } \\
\text { diretora da escola que cortaram } \\
\text { a mangueira de combustível }\end{array}$ & $17 \mathrm{~h} 06 \mathrm{~min}$ \\
\hline Caso 2 - Charles e Vitor & $\begin{array}{c}\text { Cursa a } 7^{\mathrm{a}} \text { série junto à escola } \\
{[\ldots] \text { no período da tarde }}\end{array}$ & $17 \mathrm{~h} 22 \mathrm{~min}$ \\
\hline Caso 6 - Beatriz & $\begin{array}{c}\text { Declarante estuda na } 5^{\mathrm{a}} \text { série no } \\
\text { período da tarde }\end{array}$ & $15 \mathrm{~h} 49 \mathrm{~min}$ \\
\hline Caso 7 - Beatriz & $\begin{array}{c}\text { Declarante estuda na } 5^{\mathrm{a}} \text { série no } \\
\text { período da tarde }\end{array}$ & $16 \mathrm{~h} 22 \mathrm{~min}$ \\
\hline
\end{tabular}

Fonte: GOETHEL, 2016.*Horário da elaboração do B.O. na delegacia com a presença do(a) adolescente.

Quando pensamos que a escola, representada pela sua equipe gestora, decidiu pedir a intervenção da PM e aceitou que os alunos fossem conduzidos em horário de aula, questionamo-nos: "Qual era a intenção da condução dos adolescentes até a repartição policial?” Resolver o conflito? Transferir o problema? Penalizar o adolescente? Fazer dessa ação um exemplo de punição para os demais estudantes? Desconhecimento do ECA (princípio do melhor interesse da criança e do adolescente)? Falta de condições/inabilidade da escola para resolver o conflito? Estaria a escola sobrecarregada?

O Brasil, como signatário da Convenção Internacional dos Direitos da Criança e Adolescente, por meio do Decreto n. 99.710/90, indica, em seu artigo 3.1, que “[...] devem considerar, primordialmente, o interesse maior da criança" (BRASIL, 1990, tradução oficial).

Considerando esse princípio, a condução dos estudantes em horário de aula consistiria na atitude correta a ser adotada pela equipe escolar? O B.O. já havia sido registrado no local e os estudantes estavam em horário de aula. Portanto, poderia ter sido garantido primordialmente o direito à educação, deixando-os na escola, já que a condução deles até a delegacia se fez desnecessária em nossa análise. Refletimos com Heckert e Rocha (2012), ao afirmarem que: 
esta judicialização tem se caracterizado pela expansão da ação da justiça no território da escola, com o aparato jurídico sendo acionado para intervir em conflitos que emergem no chão da escola e/ou para esclarecer dúvidas, muito mais quanto aos deveres não cumpridos do que com relação aos direitos sociais não garantidos. A lógica judicial passa a permear o cotidiano escolar, ofertada e requisitada, principalmente, para manter a ordem. Utilizando-se de ameaças de punição, intensifica-se a criminalização de ações que interrogam as práticas instituídas, forjando-se políticas do medo e do controle do suposto risco social (HECKERT; ROCHA, 2012, p. 90).

A afirmação, feita por Foucault, de que "o sistema escolar é também inteiramente baseado em uma espécie de poder judiciário. A todo o momento se pune e se recompensa, se avalia, se classifica, se diz quem é o melhor, quem é o pior" (2003, p. 120), parece se confirmar em nossa análise dos processos.

Ainda outro elemento que pode fortalecer a ideia de castigo dado pela escola é o não comparecimento das vítimas nas etapas de apuração do ato infracional. Verificamos, nos boletins de ocorrência, que em nenhum momento as vítimas (inspetora/professora/diretora) ou um representante da instituição de ensino esteve presente na delegacia no registro dos documentos, como observado em Goethel (2016):

A vítima não estava presente no plantão quando da lavratura do boletim de ocorrência (Caso 1, fl.06).

A professora, dizente vítima, não se fez presente no plantão policial (Caso 3, fl. 05).

A vítima não estava presente no plantão policial (Caso 6, fl. 08).

A vítima fez-se ausente no plantão policial (Caso 7, fl. 11-12).

Essa ação reforça a compreensão da escola de que, se o problema foi registrado pela polícia, não caberia mais a ela a responsabilidade do caso, o que destoa da fala frequente de professores e gestores de que eles não ficam sabendo sobre os desdobramentos dos casos encaminhados aos outros órgãos. A falta de envolvimento e de acompanhamento do problema pela escola contribui para o entendimento, de senso comum, de que o registro do boletim de ocorrência "não dá em nada". Além disso,

essa expressão também revela o quanto é pouco (ou quase nenhum) o conhecimento dos trâmites do Poder Judiciário, das suas burocracias e desdobramentos. Muitas vezes, o que acontece é que, por ser um processo demorado, o aluno envolvido no ato judicializado acaba abandonando a escola antes de o processo se concluir. Mais sério ainda éo fato de serem conduzidos desacompanhados de um responsável e com o consentimento da equipe gestora, quando sob responsabilidade da escola, em horário escolar. Essa ação configura violação de direito, se observarmos o que está prescrito no ECA (GOETHEL, 2016, p. 97).

Cabe registrar que a relação da polícia com os adolescentes considerados autores de ato infracional e suas famílias, conforme relatado por uma mãe em um dos processos analisados, revela que são muito humilhados e destratados por policiais e pela justiça. Conta-se ser abusivas as atitudes dos policiais para com seus filhos, machucando-os. A mãe em questão salienta que os policiais a ameaçaram, falando que iam "tirar mais um filho" dela, numa analogia a seu outro filho, que estava preso (relatório CREAS).

Lembramos que a autoridade de um policial não dá a ele o direito de agredir física ou verbalmente 
qualquer pessoa. $\mathrm{O}$ abuso de poder utilizado por alguns profissionais viola e rompe direitos constitucionais que devem ser garantidos. A humilhação constitui estratégia de aniquilamento do sujeito, desabilitando-o a buscar por seus direitos.

A trajetória de vida dos adolescentes considerados autores de atos infracionais é geralmente caracterizada por sucessivas situações reais e subjetivas de exclusão. Contraditoriamente, ao cometeram delito, os adolescentes passam a ser sujeitos de garantias e de direitos, principalmente quando privados de liberdade, fato que sua condição anterior não lhes permitiria. Essa relação se mostra contraditória, porém insuficiente para garantir o acesso a esses direitos (CASTRO; GUARESCHI, 2008).

Como se pode observar, no Caso 4, consta no B.O. que Fernando (12 anos) e Natália (11 anos) se agrediram dentro da sala de aula, sem terem causado lesões corporais um ao outro (GOETHEL, 2016). Esse caso nos parece sem gravidade, com possibilidade de resolução em ambiente escolar. Entretanto, não consta no processo que tenha havido, por parte da escola, a busca pela conversa com os pais dos estudantes envolvidos antes da criminalização do fato. O representante do Ministério Público terminou por oferecer a remissão ao envolvido por avaliar o ato sem gravidade. Na manifestação ao Juiz, o promotor escreveu:

Conforme consta no boletim de ocorrência [...], os adolescentes Fernando e Natália, essa ainda criança na data do fato, agrediram-se mutuamente na sala de aula, sem deixar lesões corporais. O adolescente Fernando não compareceu à promotoria de justiça para oitiva informal, conforme notificação. Pois bem. Considerando sem gravidade o ato infracional, e as circunstâncias do fato, vislumbro inútil o prosseguimento do feito, motivo pelo qual concedo ao adolescente Fernando a REMISSÃO pura e simples, como forma de exclusão do processo (Caso 4, fl. 16).

Parece estar se constituindo uma naturalização de práticas opressivas no ambiente escolar, ao oferecer denúncia em situações como a apresentada. A transferência, para o Sistema de Justiça, de demandas, muitas vezes, de indisciplina e questões próprias à convivência escolar parece buscar a conformação de comportamentos, por meio da qual a docilização de corpos e mentes está associada a uma expectativa de educar pelo temor à punição, colocando em xeque a ideia de escola como espaço de proteção e inclusão social, potencializador das relações sociais (AGUINSKY; SILVA; PACHECO, 2014).

No Procedimento de Apuração do Ato Infracional, no último caso apresentado, chama a atenção a atitude da escola diante do ocorrido, qual seja: a intervenção policial. Cabe questionar se a equipe gestora teria refletido sobre sua atitude, haja vista que o próprio Ministério Público não achou necessários maiores esclarecimentos sobre o fato e avaliou que esse não apresentava gravidade. $\mathrm{O}$ despreparo das instituições, por vezes, contribui para o agravamento da situação, quando poderia haver aparato protetivo para a não entrada ou a saída da criminalidade.

Consideramos fundamental refletir sobre o modo como a escola entende os conflitos escolares e as consequências psicossociais para os alunos criminalizados, consequentemente transformados em perigosos ao terem questões escolares judicializadas (Rosa et al., 2011). Observamos que a escola tem se colocado como impotente na resolução de conflitos escolares e, quando diante de situações como as relatadas, opta por medidas repressivas, utilizando-se do recurso da transferência compulsória, que se apresenta para o aluno como expulsão/punição. Para Camacho (2000, p. 42), expulsando, a escola não soluciona, mas se livra momentaneamente do problema e, por vezes, acaba cometendo, ela também, uma violência, porque deseja mostrar para os demais alunos sua autoridade punitiva.

Partimos do pressuposto de que a escola constitui espaço privilegiado e potencializador para o desenvolvimento socioeducativo de crianças e adolescentes, principalmente para aqueles que se envolvem 
em situações de conflito. Nessa perspectiva, a educação pode se configurar como possibilidade para reduzir o envolvimento de jovens em atos infracionais. No entanto, é necessário que a escola assuma seu papel e que se organize para conhecer e compreender os alunos que atende, buscando observar necessidades e interesses de crianças e adolescentes, o que pode passar pela ressignificação do processo de escolarização para aqueles que já passaram por ela. Esse movimento só se estabelece, trabalhando preventiva e significativamente para aqueles que estão em seu cotidiano. Necessidades e interesses são aqui compreendidos como social e historicamente produzidos, ou seja, como importante recurso na educação, ao produzirem, dialeticamente, nos estudantes, novas curiosidades e buscas pelo conhecimento e pelo que a escola pode oferecer para sua formação humana.

A judicialização dos conflitos ocorridos dentro da escola traz consigo um alarde acerca da fragilidade da instituição no tocante a dar suporte aos fatos, deixando de tratá-los em seu ambiente de origem e sendo necessária a intervenção do Poder Judiciário para sua resolução (ÁVILA, 2013). Isso constitui grande falácia, haja vista que os processos judiciais não têm a potencialidade de ressignificar o ato praticado na escola, assim como não permitem o entendimento da dinâmica do conflito. Dessa maneira, a resolução de grande parte dos conflitos escolares continua potencializada no cotidiano da escola e em seus criativos recursos pedagógicos. Como desafia Arroyo (2015), na recuperação da crença de que todo humano é educável e viável.

\section{Considerações Finais}

Após a análise cuidadosa dos casos ilustrados no estudo, observamos que influenciam o dia a dia do ambiente escolar. As situações de conflito e indisciplina são corriqueiras em um cotidiano marcado pela heterogeneidade e pela diversidade dos sujeitos, que convivem no mesmo espaço e para lá transportam suas experiências vividas e realidades.

Nesse contexto é que ocorre o princípio da judicialização dos atos cometidos pelos jovens estudantes, tomados pela escola como ações violentas e tratados como atos infracionais, os quais, posteriormente, transformam-se em objeto da aplicação de medidas socioeducativas.

As circunstâncias de violência que se dão no âmbito da escola estão sendo encaminhados para o Sistema de Justiça, repassando as imputações da escola para o sistema judicial. Esse cenário nos permite uma reflexão sobre a escola não estar disposta pedagogicamente e respaldada juridicamente para o enfrentamento das situações de conflito no cotidiano escolar. Na tentativa de solucioná-las, acaba judicializando as relações escolares.

Observa-se também, que escola, conhecida como espaço de socialização, tem decidido por ações que acabam ferindo o direito à educação de muitos estudantes atendidos pela instituição. Como exemplo, podemos indicar o episódio de um aluno encaminhado à delegacia de polícia em horário de aula, contrariando o "melhor interesse do adolescente", conforme previsto no ECA (BRASIL, 1990).

A judicialização dos conflitos escolares pode ser sugestiva de uma fragilidade da escola no tocante à resolução de conflitos e problemas cotidianos, bem como pode apontar falhas ou deficiências na interlocução com as demais instituições da rede de atendimento a crianças e adolescentes. Essas dificuldades, entre outras, conduzem às intervenções do Poder Judiciário, configurando uma saída para os problemas conflitivos e uma falácia, como ficou claro na análise e na discussão dos processos judiciais. Vimos que não há entendimento e/ou ressignificação dos atos praticados pelos jovens no contexto da escola.

Como foi observado, a maioria dos casos judicializados pela escola terminou arquivada depois de aplicada a remissão ao processo. Evidencia-se que casos de baixo potencial ofensivo, os quais, na maioria das vezes, podem ser resolvidas em uma intervenção pedagógica realizada pela própria escola, como em situações de indisciplina ou ameaça ao patrimônio, acabam sendo tratados como casos de polícia. Entendemos que essas ações, as quais têm como foco a judicialização, parecem despotencializar a escola e sua equipe de sua 
autoridade educativa, perdendo-se, assim, a oportunidade para a atuação em seu melhor papel, qual seja: como a instituição com melhores condições para desenvolvimento de ações democráticas que possibilitem o enfrentamento dos conflitos, indisciplinas e incivilidades (desrespeito às regras da escola).

\section{Financiamento}

Conselho Nacional de Desenvolvimento Científico e Tecnológico

[https://doi.org/10.13039/501100003593]

Grant \#480714/2013-4

\section{Contribuição das Autoras}

Problematização e Conceituação, Goethel ESQ, Polido C, Fonseca DC; Metodologia, Goethel ESQ, Polido C, Fonseca DC; Análise, Goethel ESQ, Polido C, Fonseca DC; Redação, Goethel ESQ, Polido C, Fonseca DC.

\section{REFERÊNCIAS}

ARROYO, M. G. O humano é viável? É educável? Revista Pedagógica, v. 17, n. 35, maio-ago. 2015. https:// doi.org/10.22196/rp.v17i35.3052

AGUINSKY, B. G.; SILVA, G. M.; PACHECO, C. L.; ÁVILA, L. F. Judicialização dos conflitos escolares: Desafios para a materialização dos princípios do SINASE, 2014. Disponível em: <http://ebooks.pucrs.br/ edipucrs/anais/serpinf/2014/assets/21.pdf>. Acesso em: 01 abr. 2016.

ÁVILA, L. F. As medidas socioeducativas em meio aberto e a relação com a judicialização das violências nas escolas na cidade de Porto Alegre. 2013. Dissertação (Mestrado em Serviço Social) - Faculdade de Serviço Social, PUC-RS, Porto Alegre, 2013.

BRASIL. Constituição Federal do Brasil, 1988.

BRASIL. Estatuto da Criança e do Adolescente, Lei n. 8.069 de 12 jul. 1990.

BRASIL. Lei de Diretrizes e Bases da Educação, 1996.

CAMACHO, L. M.Y. Violência e indisciplina nas práticas escolares de adolescentes: Um estudo das realidades de duas escolas semelhantes e diferentes entre si. 2000. Tese (Doutorado em Educação) - Programa de Pós-Graduação em Educação da Faculdade de Ciências e Tecnologia, Universidade de São Paulo, 2000.

CASTRO, A. L. S.; GUARESCHI, P. Da privação da dignidade social à privação da liberdade individual. Psicologia \& Sociedade, v. 20, n. 2, p. 200-207, 2008. https://doi.org/10.1590/S0102-71822008000200007 
DAYRELL, J. Juventude, socialização e escola. In: DAYRELL, J.; CARRANO, P.; MAIA, C. L. (orgs.). Juventude e Ensino Médio: Sujeitos e currículo em diálogo. Belo Horizonte: UFMG, 2014, p. 298-322.

DUBET, F. A escola e a exclusão. Cadernos de Pesquisa, n. 119, p. 29-45, 2003.

FOUCAULT, M. A verdade e as formas jurídicas. Rio de Janeiro: Nau/PUC-Rio, 2003.

FRAGOSO, H. C. Lições de Direito Penal: Parte geral. Rio de Janeiro: Forense, 2003, p.70-73.

GOETHEL, E. S. Q. A ação dos atores jurídico-sociais em processos judiciais de estudantes. 2016. Dissertação (Mestrado em Educação) -Programa de Pós-graduação em Educação, Instituto de Biociências - Universidade Estadual Paulista, Rio Claro, 2016. 147 f.

HECKERT, A. L.; ROCHA, M. L. A maquinaria escolar e os processos de regulamentação da vida. Psicologia \& Sociedade, v. 24, n. especial, p. 85-93, 2012. https://doi.org/10.1590/S0102-71822012000400013

IBGE [Instituto Brasileiro de Geografia e Estatística]. Diretoria de Pesquisas, Coordenação de Trabalho e Rendimento. Pesquisa Nacional por Amostra de Domicílios Contínua 2017-2018. IBGE, 2019. ISBN 978-85-240-4495-3.

LAHIRE, B. Homem plural: Os determinantes da ação. Petrópolis: Vozes, 2002.

LEONTIEV, A. N. O desenvolvimento do psiquismo. São Paulo: Ed. Moraes Ltda, 1978.

REY, F. G. Personalidade, saúde e modo de vida. São Paulo: Pioneira Thomson Learning, 2004.

ROSA, M. D.; VICENTIM, M. C.; BROIDE, J. Direitos humanos e interfaces psi-jurídicas: Uma pauta éticopolítica para a questão dos adolescentes "perigosos". In: CONSELHO REGIONAL DE PSICOLOGIA DA 6a. REGIÃO (org.). Psicologia, violência e direitos humanos. São Paulo: CRP SP, 2011, p.78-94.

SCHMIDT, D. P. Violência como uma expressão da questão social: Suas manifestações e seu enfrentamento no espaço escolar. 2007. Dissertação (Mestrado em Educação) - Programa de Pós-graduação em Educação, Universidade Federal de Santa Maria, Santa Maria, 2007. 84 f.

VIGOTSKI, L.S. A construção do pensamento e da linguagem. São Paulo: Martins Fontes, 2001.

ZALUAR, A; LEAL, M. C. Violência extra e intramuros. Revista BrasIleira de Ciências Sociais, São Paulo, v.16, n. 45, p.145-164, fev. 2001. https://doi.org/10.1590/S0102-69092001000100008

Recebido: 01 Mar 2019

Aceito: 17 Set 2019

Comitê Editorial do Cedes/Coordenação deste número:

Izabel Galvão e Maria Rosa Camargo 